\title{
Preoperative nutritional support for patients undergoing elective colorectal cancer surgery - does it really work?
}

\author{
Milan Tesara, ${ }^{\mathrm{a} b}$, Veronika Kozusnikova ${ }^{\mathrm{a}}$, Lubomir Martinek ${ }^{\mathrm{a}, \mathrm{b}}$, Stefan Durdikc, Peter Ihnat ${ }^{\mathrm{a}, \mathrm{b}}$
}

\begin{abstract}
Aims. This study aimed to evaluate the effect of preoperative administration of oral nutritional supplements (ONS) on the self-sufficiency, physical status, and nutritional status of patients undergoing elective colorectal resections. Methods. This prospective randomized clinical trial was conducted in a single institution. Patients scheduled to undergo colorectal cancer surgery were randomized to either ONS twice per day for 7 days before surgery or no ONS. Results. We enrolled 120 patients in the study. The two study groups had comparable hospital stay times and comparable numbers of postoperative complications. Laboratory parameter (albumin and prealbumin) values declined in the postoperative period, but differences between study groups were not significant. The groups had comparable arm circumference measurements, muscle mass and fat proportions, and water weights. Patient self-sufficiency in the postoperative period was comparable between groups $(P=0.313)$. Lower limb force declined after surgery, but differences between the groups were not significant $(P=0.579)$.

Conclusion. Preoperative administration of ONS to patients undergoing elective colorectal surgery did not reduce postoperative morbidity or enhance recovery. Moreover, patient self-sufficiency, physical status, and nutritional status were not influenced by preoperative ONS. Patients should be properly selected for malnourishment before providing nutritional support to manage costs efficiently.
\end{abstract}

Trial Registration: ClinicalTrials.gov (NCT03930888).

Key words: nutritional supplements, malnutrition, colorectal cancer, self-sufficiency, postoperative morbidity

Received: December 8, 2021; Revised: January 28, 2022; Accepted: February 14, 2022; Available online: March 1, 2022 https://doi.org/10.5507/bp.2022.009

(c) 2022 The Authors; https://creativecommons.org/licenses/by/4.0/

${ }^{a}$ Department of Surgery, University Hospital Ostrava, 17. listopadu 1790, Ostrava 708 52, Czech Republic ${ }^{b}$ Department of Surgical Studies, Faculty of Medicine, University of Ostrava, Syllabova 19, Ostrava 70300 , Czech Republic 'Department of Oncosurgery, Faculty of Medicine, Commenius University, Spitalska 24, Bratislava 813 72, Slovak Republic Corresponding author: Peter Ihnat, e-mail:peterihnat@yahoo.com

\section{INTRODUCTION}

Colorectal cancer is the most common cancer of the gastrointestinal tract and the second most frequently diagnosed malignancy in adults ${ }^{1}$. The presence of malignancy can induce weight loss and malnutrition. It is estimated that two of every three patients with colorectal cancer lost weight preoperatively, and one of every five patients lost more than $10 \%$ of their body weight ${ }^{2}$.

Malnutrition is associated with impaired wound healing after surgery, compromised defense against infections, and reduced muscle strength ${ }^{3}$. A reduction in muscle strength results in ineffective rehabilitation, impaired coughing, poor mobility, and increased risk of bronchopneumonia. It is generally accepted that patients with cancer who are malnourished should receive nutritional support prior to surgery to minimize the negative effects of malnutrition. Nutritional support is thought to modify the physiological responses to major surgery, reduce postoperative complications, shorten the hospital stay, and accelerate recovery $y^{3,4}$.

Preoperative administration of oral nutritional supplements (ONS) to patients at nutritional risk is recom- mended by The European Society for Clinical Nutrition and Metabolism (ESPEN) and the Enhanced Recovery After Surgery (ERAS) societies ${ }^{4,5}$. However, the outcomes of a recent systematic review on this topic have contradicted these recommendations. Recent review, published by E. Bruns, incorporated the results of 6 prospective clinical studies that had been realized between 2004 and 2016 (ref. ${ }^{6}$ ). They concluded that the overall complication rate was not significantly reduced in patients who $\mathrm{t}$ had received preoperative ONS $\left(\right.$ ref. $\left.^{7-12}\right)$. However, all those studies were focused on the correlation between preoperative ONS and postoperative morbidity. To the best of our knowledge, no study has investigated the impact of ONS on the physical status, nutritional status, or self-sufficiency of patients undergoing elective colorectal surgery.

The present study aimed to evaluate the effects of preoperative nutritional supplementation on the postoperative physical status, nutritional status, and self-sufficiency of patients that underwent an elective colorectal resection. 


\section{METHODS}

\section{Design and Setting}

This prospective, randomized clinical trial was designed to assess self-sufficiency, loss of muscle mass/ strength, and the possibility of returning to normal activities, when preoperative ONS was provided to patients scheduled to undergo elective surgery for colorectal cancer. The trial was conducted at the University Hospital Ostrava, Czech Republic. All patients with colorectal cancer scheduled to undergo an elective colorectal resection within the study period (1 January 2019 to 30 June 2020) were assessed for study eligibility. The study was approved by the Ethics Committee of the University Hospital Ostrava (ref. Number 447a/2018). It was performed in accordance with the ethical standards of the Declaration of Helsinki (1964) and its subsequent amendments. Written informed consent was obtained from all included patients, and anonymity was ensured. The trial was registered at http://www.clinicaltrials.gov (trial identifier NCT 03930888).

The primary outcomes were changes in muscle strength, muscle mass, and self-sufficiency in patients that underwent elective colorectal surgery, with or without preoperative ONS. The secondary outcome was the change in nutritional status of study patients. In addition, we compared postoperative surgical complications in patients with/without nutritional support.

The inclusion criteria were age $\geq 18$ years and an indication for an elective resection of colorectal carcinoma. Exclusion criteria were: a generalized disease, intestinal co-morbidity (Morbus Crohn etc.), duplicate malignancy, and incomplete data for the follow-up. Within the study period, all included patients were randomized to one of the trial arms (ONS group and no-ONS group), with the envelope randomization method (all envelopes were prepared in advance, at a ratio of 1:1).

Patients in the ONS group received oral nutritional supplements $(125 \mathrm{~mL})$, twice per day, for 7 days before surgery. Patients with diabetes received oral nutritional supplements for diabetics (200 mL), twice per day. These supplements provided patients with additional energy intakes of $2525 \mathrm{~kJ}$ or $2520 \mathrm{~kJ}$ (supplement for diabetics) per day; the additional protein intakes were $24 \mathrm{~g}$ or $30 \mathrm{~g}$ per day (supplement for diabetics).

Nutritional status was assessed with a Nutritional risk screening (NRS 2002) instrument and blood levels of prealbumin (transthyretin) and albumin $(\mathrm{g} / \mathrm{L})\left(\right.$ ref. $\left.{ }^{13}\right)$. Nutritional status was assessed on the day before surgery and on the $5^{\text {th }}$ or $6^{\text {th }}$ day after surgery. The NRS 2002 is a specialized scoring system and prognostic nutritional index, which was designed to assess malnutrition and its severity. The NRS 2002 was recommended by the ESPEN for routine use in clinical practice ${ }^{4}$.

We assessed postoperative surgical complications according to the Clavien-Dindo classification system ${ }^{14}$. We measured muscle strength, muscle mass, and patient selfsufficiency on the day before surgery and on the $5^{\text {th }}$ or $6^{\text {th }}$ day after surgery. Muscle strength was measured dynamo- metrically (expressed in $\mathrm{kg}$ ) by rehabilitation workers. We measured body weight and analyzed the proportions of muscle, fat, and water in the body with a TANITA MC780 MA body analyzer (expressed in \% of whole-body weight).

We assessed self-sufficiency with the Barthel Index for Activities of Daily Living. The Barthel Index comprised ten variables for describing activities of daily living and mobility. The amount of time and physical assistance required to perform each activity were rated on a scale of $0-100$. Higher numbers were associated with a greater likelihood of living at home with a degree of independence following hospital discharge.

\section{Data collection}

All data were collected prospectively. All presurgical demographic and clinical data on study patients, including age, sex, body mass index (BMI, $\mathrm{kg} / \mathrm{m}^{2}$ ), tumor localization, pTNM classification, carcinoembryonic antigen (CEA) value, and NRS 2002 value, were entered into the study database before surgery. One day before surgery, and on the $5^{\text {th }}$ or $6^{\text {th }}$ day after surgery, the following data (measurements) were recorded: body mass $(\mathrm{kg})$; blood levels of albumin level $(\mathrm{g} / \mathrm{L})$, prealbumin $(\mathrm{g} / \mathrm{L})$, creatinine $(\mathrm{mmol} / \mathrm{L})$, and $\mathrm{C}$-reactive protein $(\mathrm{CRP}, \mathrm{mg} / \mathrm{L})$; body weight; the percentages of muscle, water, and fat in the body (\%); arm circumference (cm); muscular strength of the upper and lower limbs $(\mathrm{kg})$; and the Barthel index score. The time spent in the intensive care unit (ICU, days), the hospital stay (days), and the 30-day postoperative complications were recorded during follow-up.

\section{Statistical analysis}

We performed standard descriptive statistics, and continuous data are expressed as the mean, standard deviation (SD) or the median (range). Categorical data are expressed as the frequency. Comparisons were performed with the t-test, ANOVA, Fisher, or Kruskal-Wallis test, according to the nature of the data, and the chi-square test. $P$-values $\leq 0.05$ were considered significant. All analyses were performed with the mathematical-statistical programs available from the R-project (The R Foundation for Statistical Computing).

\section{RESULTS}

Within the study period (1 January 2019 to 30 June 2020), 251 patients met the inclusion criteria and were assessed for study eligibility. Of these, 66 (26\%) patients were excluded, based on the exclusion criteria, and 62 patients $(24.7 \%)$ declined to participate in the study (CONSORT diagram, Fig. 1). In total, 120 patients with complete data were enrolled in the study.

The patient demographics and clinical characteristics are presented in Table 1. The mean age of the patients was $65.3 \pm 11.5$ years $(\mathrm{SD})$; there were $41(34.2 \%)$ women and $79(65.8 \%)$ men. The mean BMI on the day of admission was $26.6 \pm 5.41 \mathrm{~kg} / \mathrm{m}^{2}$. Tumors were localized in the 
Table 1. Demographics and preoperative status of patients that underwent surgery for colorectal cancer.

\begin{tabular}{|c|c|c|c|c|}
\hline Parameter & $\begin{array}{c}\text { All } \\
\mathrm{n}=(120)\end{array}$ & $\begin{array}{c}\text { Intervention } \\
(\mathrm{n}=60)\end{array}$ & $\begin{array}{l}\text { Control } \\
(\mathrm{n}=60)\end{array}$ & $P$ \\
\hline \multicolumn{5}{|l|}{ Sex, n (\%) } \\
\hline Female, & $41(34.2 \%)$ & $17(28.3 \%)$ & $24(40.0 \%)$ & \multirow[t]{2}{*}{0.248} \\
\hline Male & $79(65.8 \%)$ & $43(71.7 \%)$ & $36(60.0 \%)$ & \\
\hline Age (years) Mean \pm SD & $65.3 \pm 11.5$ & $67.5 \pm 10.0$ & $63.1 \pm 12.5$ & 0.034 \\
\hline Admission BMI $\left(\mathrm{kg} / \mathrm{m}^{2}\right)$, Mean $\pm \mathrm{SD}$ & $26.6 \pm 5.41$ & $27.2 \pm 4.79$ & $26.0 \pm 5.83$ & 0.382 \\
\hline \multicolumn{5}{|l|}{ Stage, n (\%) } \\
\hline I & $44(36.7 \%)$ & $21(35.0 \%)$ & $23(38.3 \%)$ & \multirow{3}{*}{0.745} \\
\hline II & $42(35.0 \%)$ & $23(38.3 \%)$ & $19(31.7 \%)$ & \\
\hline III & $34(28.3 \%)$ & $16(26.7 \%)$ & $18(30.0 \%)$ & \\
\hline CEA value $(\mu \mathrm{g} / \mathrm{L})$, Mean $\pm \mathrm{SD}$ & $10.00 \pm 29.1$ & $14.2 \pm 39.6$ & $5.79 \pm 9.83$ & 0.115 \\
\hline \multicolumn{5}{|l|}{ Localization of tumor, n (\%) } \\
\hline Right colon & $43(35.8 \%)$ & $24(40.0 \%)$ & $19(31.7 \%)$ & \multirow{3}{*}{0.171} \\
\hline Left colon & $29(24.2 \%)$ & $17(28.3 \%)$ & $12(20.0 \%)$ & \\
\hline Rectum & $48(40.0 \%)$ & $19(31.7 \%)$ & $29(48.3 \%)$ & \\
\hline \multicolumn{5}{|l|}{ Surgical technique, n (\%) } \\
\hline Laparoscopy & $91(75.8 \%)$ & $50(83.3 \%)$ & $41(68.3 \%)$ & \multirow[t]{2}{*}{0.088} \\
\hline Laparotomy & $29(24.2 \%)$ & $10(16.7 \%)$ & $19(31.7 \%)$ & \\
\hline
\end{tabular}

Table 2. Pre- and post-operative nutritional parameters in patients that underwent surgery for colorectal cancer.

\begin{tabular}{|c|c|c|c|c|}
\hline Parameter & $\begin{array}{c}\text { All } \\
(n=120)\end{array}$ & $\begin{array}{l}\text { Intervention } \\
(\mathrm{n}=60)\end{array}$ & $\begin{array}{l}\text { Control } \\
(\mathrm{n}=60)\end{array}$ & $P$ \\
\hline \multicolumn{5}{|l|}{ BMI $\left(\mathrm{kg} / \mathrm{m}^{2}\right)$, Mean \pm SD } \\
\hline Admission & $26.6 \pm 5.41$ & $27.2 \pm 4.79$ & $26.0 \pm 5.83$ & 0.382 \\
\hline Follow up & $25.2 \pm 7.12$ & $25.9 \pm 7.62$ & $24.6 \pm 6.60$ & 0.342 \\
\hline \multicolumn{5}{|l|}{ Albumin $(g / L)$, Mean \pm SD } \\
\hline Admission & $39.5 \pm 4.14$ & $39.9 \pm 4.35$ & $39.1 \pm 3.93$ & 0.332 \\
\hline Follow up & $34.4 \pm 4.87$ & $35.2 \pm 4.96$ & $33.7 \pm 4.70$ & 0.098 \\
\hline \multicolumn{5}{|l|}{ Prealbumin $(\mathrm{g} / \mathrm{L})$, Mean $\pm \mathrm{SD}$} \\
\hline Admission & $0.22 \pm 0.06$ & $0.22 \pm 0.06$ & $0.21 \pm 0.05$ & 0.682 \\
\hline Follow up & $0.15 \pm 0.04$ & $0.15 \pm 0.04$ & $0.14 \pm 0.05$ & 0.460 \\
\hline Admission NRS 2002, Mean \pm SD & $2.25 \pm 1.42$ & $2.33 \pm 1.40$ & $2.17 \pm 1.45$ & \multirow{2}{*}{0.532} \\
\hline Admission NRS 2002 over 3, n (\%) & $35(29.2)$ & $18(30 \%)$ & $17(28.3 \%)$ & \\
\hline \multicolumn{5}{|l|}{ Weight loss n (\%) } \\
\hline Pre-operation & $43(35.6)$ & $19(31.7)$ & $24(40)$ & 0.445 \\
\hline More than $10 \%$ of body weight & $26(21.7)$ & $13(21.7)$ & $13(21.7)$ & 1 \\
\hline
\end{tabular}

rectum in $40.0 \%$ of patients. Stage I colorectal carcinoma was diagnosed in $35.8 \%$ of study patients. Laparoscopic resections were performed in $75.8 \%$ of patients.

Data on the nutritional status of study patients are shown in Table 2. According to the principles of the NRS 2002, all study patients were nutritionally at risk (i.e. all patients were seriously ill, due to colorectal cancer). The mean NRS score was $2.25 \pm 1.42$ in the entire study group before surgery. We identified 35 (29.2\%) patients that were malnourished (NRS score $\geq 3$ points). The two study subgroups had comparable NRS scores $(P=0.532)$. We found that $43(35.8 \%)$ patients had lost weight prior to surgery, and $26(21.7 \%)$ patients had lost more than $10 \%$ of their body weight.

The perioperative outcomes (i.e., hospital stay, ICU stay. and postoperative complications) are presented in Table 3. The mean hospital and ICU stays were comparable between study groups $(P=0.855$ and $P=0.073$, respec- tively). The 30-day postoperative surgical morbidity was $34 \%$. Minor complications (Clavien-Dindo grades I-II) were noted in 32 (26.6\%) study patients. Serious postoperative complications (Clavien-Dindo grades III-V) were observed in $9(7.5 \%)$ patients. The prevalence of postoperative complications was comparable between study groups $(P=0.73)$. The 30 -day postoperative mortality was $0.8 \%$ (one patient with multiple organ failure died, due to anastomosis dehiscence after a right hemicolectomy).

Changes in patient nutritional parameters are reported in Table 2. The mean BMI dropped from $26.6 \pm 5.41$ to $25.2 \pm 7.12 \mathrm{~kg} / \mathrm{m}^{2}$ on the fifth postoperative day. The decline in BMI was similar in both groups $(P=0.342)$. The monitored laboratory parameters (albumin and prealbumin) also declined in the postoperative period. The mean albumin level dropped from $39.5 \pm 4.14 \mathrm{~g} / \mathrm{L}$ to 34.4 $\pm 4.87 \mathrm{~g} / \mathrm{L}$, and the mean prealbumin levels dropped from $0.22 \pm 0.06 \mathrm{~g} / \mathrm{L}$ to $0.15 \pm 0.04 \mathrm{~g} / \mathrm{L}$. Although the declines 
of these parameters were more noticeable in the no-ONS group than in the ONS group, the differences between groups were not significant $(P=0.098$ and $P=0.460$, respectively).

Parameters related to body composition, muscle strength, and self-sufficiency are presented in Table 4. The analysis of body composition before surgery revealed that the mean proportion of muscle mass was $69.9 \% \pm 8.5$, the mean proportion of water was $51.2 \% \pm 6.3$, and the mean proportion of fat was $28.3 \% \pm 10.5$. The proportions of muscle mass and water weight were not significantly different between groups. Patients in the no-ONS group had a lower mean fat percentage than patients in the ONS group, but the difference was not statistically significant ( $P=0.108$ before surgery, $P=0.095$ after surgery). The

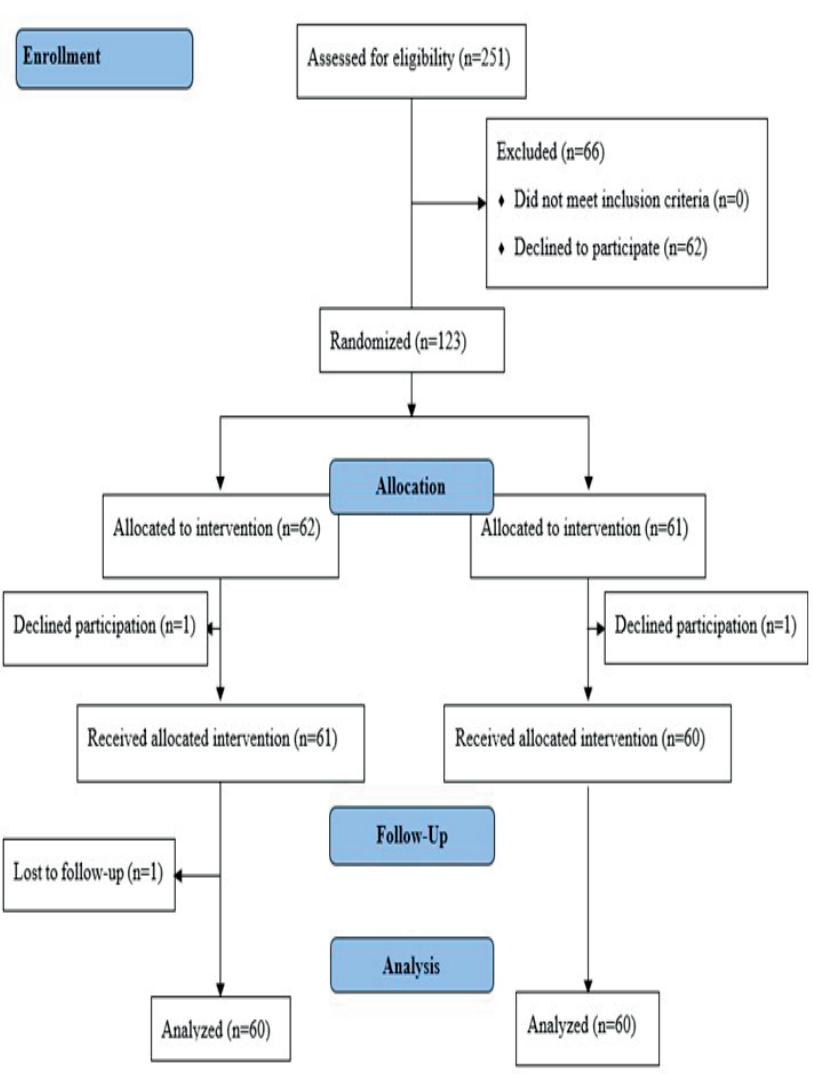

Fig. 1. CONSORT diagram. groups had comparable preoperative and postoperative arm circumference measurements ( $P=0.157$ and $P=0.118$, respectively).

Self-sufficiency (assessed with the Barthel index) was comparable between groups, before and after surgery ( $P=0.862$ and $P=0.313$, respectively). Dynamometric measurements showed that muscular strength in the upper limbs did not change after the surgery (preoperative values were nearly equal to postoperative values). There was a slight reduction in the force of the lower limbs after surgery (mean preoperative strength $15.6 \pm 4.53 \mathrm{~kg}$, and mean postoperative strength $14.6 \pm 4.61 \mathrm{~kg}$ ), but no significant difference was observed between groups (preoperative $P=0.496$ and postoperative $P=0.579$ ).

\section{DISCUSSION}

To the best of our knowledge, all previous clinical studies were focused on the correlation between ONS and postoperative morbidity. In contrast, the primary focus of the present study was to investigate the effect of ONS on physical status, nutritional status, and postoperative self-sufficiency. Thus, the innovative concept of our study provided data on different aspects of perioperative nutritional support.

Our patients had demographic and clinical characteristics comparable to those reported in recent nutritional clinical studies that were subsequently cited in various meta-analyses ${ }^{6-10,15-17}$. According to the NRS 2002 score, all of our study patients were at nutritional risk; however, malnutrition was diagnosed in only $29.2 \%$ of patients. Colorectal cancer had induced weight loss in $35.6 \%$ of patients. The prevalences of nutritional risk and malnourishment in our study were consistent with those reported previously $^{2,18-20}$.

Previous studies have unequivocally shown that malnutrition was associated with many negative postsurgical consequences, such as impaired wound healing, decreased muscle strength, compromised defense against infections, prolonged recovery after surgery etc. ${ }^{3,21-23}$. Without doubt, malnourished patients should receive ONS prior to surgery. However, these patients represent a minor proportion of patients that undergo elective colorectal cancer surgery.

Table 3. Perioperative outcomes of patients that underwent surgery for colorectal cancer.

\begin{tabular}{|c|c|c|c|c|}
\hline Parameter & $\begin{array}{c}\text { All } \\
(n=120)\end{array}$ & $\begin{array}{c}\text { Intervention } \\
(n=60)\end{array}$ & Control $(n=60)$ & $P$ \\
\hline \multicolumn{5}{|l|}{ Complications, $\mathrm{n}(\%)$} \\
\hline Clavien-Dindo I & $23(19.2 \%)$ & $14(23.3 \%)$ & $9(15.0 \%)$ & \multirow{5}{*}{0.520} \\
\hline Clavien-Dindo II & $9(7.50 \%)$ & $3(5.00 \%)$ & $6(10.0 \%)$ & \\
\hline Clavien-Dindo III & $7(5.83 \%)$ & $4(6.67 \%)$ & $3(5.00 \%)$ & \\
\hline Clavien-Dindo IV & $1(0.83 \%)$ & $0(0.00 \%)$ & $1(1.67 \%)$ & \\
\hline Clavien-Dindo V & $1(0.83 \%)$ & $1(1.67 \%)$ & $0(0.00 \%)$ & \\
\hline All & $41(34.2 \%)$ & $22(36.7 \%)$ & $19(31.7 \%)$ & 0.73 \\
\hline ICU stay (days), Mean \pm SD & $3.94 \pm 3.13$ & $3.42 \pm 2.46$ & $4.45 \pm 3.61$ & 0.073 \\
\hline Hospital stay (days), Mean \pm SD & $11.0 \pm 8.45$ & $10.9 \pm 8.95$ & $11.2 \pm 8.00$ & 0.855 \\
\hline
\end{tabular}


Table 4. Pre- and post-operative body composition, muscle strength, and self-sufficiency in patients that underwent surgery for colorectal cancer.

\begin{tabular}{|c|c|c|c|c|}
\hline Parameter & $\begin{array}{c}\text { All } \\
(n=120)\end{array}$ & $\begin{array}{c}\text { Intervention } \\
(\mathrm{n}=60)\end{array}$ & $\begin{array}{l}\begin{array}{l}\text { Control } \\
(\mathrm{n}=60)\end{array} \\
\end{array}$ & $P$ \\
\hline \multicolumn{5}{|c|}{ Muscle weight (\%), Mean \pm SD } \\
\hline Admission & $69.6 \pm 8.5$ & $67.3 \pm 8.2$ & $71.9 \pm 8.2$ & 0.607 \\
\hline Follow up & $70.1 \pm 8.2$ & $67.7 \pm 7.4$ & $72.3 \pm 8.3$ & 0.645 \\
\hline \multicolumn{5}{|c|}{ Water weight (\%), Mean \pm SD } \\
\hline Admission & $51.2 \pm 6.3$ & $52.6 \pm 6.1$ & $49.7 \pm 6.2$ & 0.724 \\
\hline Follow up & $51.2 \pm 6.1$ & $52.6 \pm 6.2$ & $49.7 \pm 5.7$ & 0.877 \\
\hline \multicolumn{5}{|c|}{ Fat weight (\%), Mean \pm SD } \\
\hline Admission & $28.3 \pm 10.5$ & $29.3 \pm 9.7$ & $27.3 \pm 10.9$ & 0.108 \\
\hline Follow up & $26.8 \pm 8.8$ & $27.6 \pm 7.7$ & $26.0 \pm 9.5$ & 0.095 \\
\hline \multicolumn{5}{|c|}{ Arm circumference $(\mathrm{cm})$, Mean $\pm \mathrm{SD}$} \\
\hline Admission & $29.7 \pm 3.95$ & $30.2 \pm 4.45$ & $29.2 \pm 3.34$ & 0.157 \\
\hline Follow up & $29.1 \pm 3.66$ & $29.7 \pm 3.89$ & $28.6 \pm 3.38$ & 0.118 \\
\hline \multicolumn{5}{|c|}{ Muscular strength of the upper limbs $(\mathrm{kg})$, Mean \pm SD } \\
\hline Admission & $10.5 \pm 3.73$ & $10.3 \pm 3.05$ & $10.8 \pm 4.32$ & 0.486 \\
\hline Follow up & $10.5 \pm 3.84$ & $10.3 \pm 3.10$ & $10.7 \pm 4.48$ & 0.560 \\
\hline \multicolumn{5}{|c|}{ Muscular strength of the lower limbs $(\mathrm{kg})$, Mean $\pm \mathrm{SD}$} \\
\hline Admission & $15.6 \pm 4.53$ & $15.8 \pm 4.33$ & $15.3 \pm 4.73$ & 0.496 \\
\hline Follow up & $14.6 \pm 4.61$ & $14.3 \pm 4.55$ & $14.8 \pm 4.70$ & 0.579 \\
\hline \multicolumn{5}{|c|}{ Barthel index (points), Mean $\pm \mathrm{SD}$} \\
\hline Admission & $96.8 \pm 5.22$ & $96.8 \pm 4.77$ & $96.9 \pm 5.68$ & 0.862 \\
\hline Follow up & $88.0 \pm 12.9$ & $89.2 \pm 9.51$ & $86.8 \pm 15.6$ & 0.313 \\
\hline
\end{tabular}

In contrast, for the majority of patients with colorectal cancer, there is no evidence that patients at nutritional risk, but not malnourished, might profit from ONS. Nevertheless, current ESPEN guidelines recommend (strong consensus, GPP grade of recommendation) perioperative nutritional therapy to all patients at nutritional risk (recommendation No. 7) $\left(\right.$ ref. $\left.^{4}\right)$. However, the published data that support this ESPEN recommendation are unconvincing.

Clinical studies published on this topic have shown contradictory outcomes. Some authors report a positive effect of preoperative ONS on the postoperative complications rate, but other studies reported no effect ${ }^{7-12}$. Several authors have found no significant effect of ONS on the postoperative course, when ONS was given to all patients undergoing colorectal cancer surgery $\mathrm{y}^{6,10,15,16}$. A recent meta-analysis published by E. Bruns failed to show a significant reduction in the overall complications rate in patients that received ONS. The same lack of effect was found for the hospital and ICU stays. ${ }^{6}$. Our study also showed no significant difference between groups regarding the postoperative morbidity, hospital stay, or ICU stay (Table 3). In fact, we found a slightly higher number of postoperative complications in patients that received ONS than in those without ONS ( $36.7 \%$ vs. $31.7 \%, P=0.73$ ).

We evaluated nutritional status with a standardized questionnaire (NRS 2002), laboratory parameters, and anthropometric measurements. Our outcomes (BMI, albumin level, prealbumin level, and the NRS 2002 score) showed that all patients with stages I - III colorectal cancer were at nutritional risk, but only $1 / 3$ were malnourished. Indeed, the nutritional parameter values measured in patients that received ONS were not significantly different than those measured in the control group. The fact that a majority of patients with colorectal cancer were not malnourished might explain why most available studies have failed to show a significant benefit of ONS for patients undergoing colorectal surgery $y^{6-10,15,16}$.

In our study, we analyzed body composition to determine whether ONS administration increased the proportion of muscle mass in patients. However, our data did not confirm this hypothesis; we recorded slight decreases in muscle mass in both study groups after surgery. Thus, according to our data, preoperative ONS had no influence on body composition or the proportion of muscle mass.

The present study focused on whether ONS administration could improve patient self-sufficiency in the postoperative period (assessed with the Barthel index). Normally, self-sufficiency declines postoperatively, as a consequence of surgical trauma and perioperative stress. As shown in Table 4, the fall in the Barthel index was more distinct among patients without ONS than among patients with ONS, but the difference was not significant. No previous study has examined the effect of ONS on patient self-sufficiency; therefore, we could not compare our findings with other data. However, two studies by Gillis and Smedley investigated the association between ONS and patient quality of life at one month after surgery. Both of those studies failed to show a higher quality of life in patients that received ONS (ref. ${ }^{11,16}$ ).

Muscular strength is an important clinical parameter that influences patient self-sufficiency and recovery after the surgery. Measurements of muscular strength provide an objective functional assessment of nutritional status; 
a decline in muscular strength is considered a sign of malnutrition and a predictor of postoperative morbidity $^{24}$. In our study, upper limb strength did not change during the postoperative period. We did observe a decline in lower limb strength after surgery, probably due to limited postoperative mobility and prolonged bed rest. However, our muscular strength measurements were not significantly different between study groups. Moreover, the dynamometric measurements did not show a positive effect of ONS on muscular strength during the postoperative period.

The strengths of this study were the study design (a prospective controlled randomized clinical trial), the innovative study concept of investigating different aspects of perioperative ONS administration, and the complex assessment of nutritional status in study patients (i.e., standardized questionnaire NRS 2002, laboratory parameters, and anthropometric measurements). Nevertheless, this study has several limitations. The study sample size was not calculated by a statistician prior to the study; the heterogeneity in operative techniques could have influenced postoperative recovery; and the limited sample size could have introduced a selection bias.

\section{CONCLUSION}

In conclusion, to the best of our knowledge, this clinical trial was unique in its aim to investigate the effects of pre-operative ONS on the physical and nutritional statuses of patients that underwent an elective colorectal resection. We found that preoperative ONS for patients undergoing elective colorectal surgery did not reduce postoperative morbidity or enhance recovery. Specifically, patient selfsufficiency, physical status, and nutritional status were not influenced by preoperative nutritional support. Although ONS administration did not harm the patient, patients should be properly selected for malnutrition before providing nutritional support to improve the cost effectiveness of this intervention.

\section{Ethics approval and consent to participate}

The study was approved by the Ethics Committee of the University Hospital Ostrava (ref. Number 447a/2018). It was performed in accordance with the ethical standards of the Declaration of Helsinki (1964) and its subsequent amendments. Written informed consent was obtained from all included patients, and anonymity was ensured. The trial was registered at http://www.clinicaltrials.gov (trial identifier NCT 03930888).

Acknowledgement: Supported by Ministry of Health, Czech Republic - conceptual development of research organization (FNOs/2018).

Author contributions: MT: data curation, investigation, project administration, original draft; VK: investigation, methodology, project administration, visualization; LM: formal analysis, methodology, review and editing; SD: conceptualization, validation, review and editing; PI: conceptualization, formal analysis, funding acquisition, methodology, resources, validation, review and editing. Conflict of interest statement: The authors state that there are no conflicts of interest regarding the publication of this article.

\section{REFERENCES}

1. Ferlay J, Colombet M, Soerjomataram I, Parkin DM, Piñeros M, Znaor A, Bray F. Cancer statistics for t44557722he year 2020: An overview. Int J Cancer 2021 Apr 5. [Epub ahead of print] doi: 10.1002/ijc.33588

2. Thoresen L, Frykholm G, Lydersen S, Ulveland H, Baracos V, Prado CM, Birdsell L, Falkmer U. Nutritional status, cachexia and survival in patients with advanced colorectal carcinoma. Different assessment criteria for nutritional status provide unequal results. Clin Nutr 2013;32(1):65-72

3. Karlsson S, Andersson L, Berglund B. Early assessment of nutritional status in patients scheduled for colorectal cancer surgery. Gastroenterol Nurs 2009;32(4):265-70.

4. Weimann $A$, Braga $M$, Carli F, Higashiguchi T, Hübner $M$, Klek $S$, Laviano A, Ljungqvist O, Lobo DN, Martindale R, Waitzberg DL, Bischoff SC, Singer P. ESPEN guideline: Clinical nutrition in surgery. Clin Nutr 2017;36(3):623-50.

5. Weimann A, Braga M, Carli F, Higashiguchi T, Hübner M, Klek S, Laviano A, Ljungqvist O, Lobo DN, Martindale R, Waitzberg DL, Bischoff SC, Singer P. Enhanced Recovery After Surgery (ERAS) Group. Consensus review of optimal perioperative care in colorectal surgery: Enhanced Recovery After Surgery (ERAS) Group recommendations. Arch Surg 2009;144(10):961-9.

6. Bruns E, Argillander TE, Van Den Heuvel B, Buskens CJ, Van Duijvendijk P, Winkels RM, Kalf A, Van Der Zaag ES, Wassenaar EB, Bemelman WA, Van Munster BC. Oral Nutrition as a Form of Pre-Operative Enhancement in Patients Undergoing Surgery for Colorectal Cancer: A Systematic Review. Surg Infect 2018;19(1):1-10.

7. Braga M, Gianotti L, Vignali A, Carlo VD. Preoperative oral arginine and $n-3$ fatty acid supplementation improves the immunometabolic host response and outcome after colorectal resection for cancer. Surgery 2002;132(5):805-14.

8. Finco C, Magnanini P, Sarzo G, Vecchiato M, Luongo B, Savastano S, Bortoliero M, Barison P, Merigliano S. Prospective randomized study on perioperative enteral immunonutrition in laparoscopic colorectal surgery. Surg Endosc 2007;21(7):1175-9.

9. Horie H, Okada M, Kojima M, Nagai H. Favorable effects of preoperative enteral immunonutrition on a surgical site infection in patients with colorectal cancer without malnutrition. Surg Today 2006;36(12):1063-8.

10. Burden ST, Hill J, Shaffer JL, Campbell M, Todd C. An unblinded randomised controlled trial of preoperative oral supplements in colorectal cancer patients. J Hum Nutr Diet 2011;24(5):441-8.

11. Gillis $C$, Loiselle SE, Fiore JF, Awasthi R, Wykes L, Liberman AS, Stein B, Charlebois P, Carli F. Prehabilitation with Whey Protein Supplementation on Perioperative Functional Exercise Capacity in Patients Undergoing Colorectal Resection for Cancer: A Pilot Double-Blinded Randomized Placebo-Controlled Trial. J Acad Nutr Diet 2016;116(5):802-12.

12. Maňásek V, Bezděk K, Foltys A, Klos K, Smitka J, Smehlik D. The Impact of High Protein Nutritional Support on Clinical Outcomes and Treatment Costs of Patients with Colorectal Cancer. Vliv nutriční podpory s vysokým obsahem bílkovin na výsledky léčby a náklady u pacientů s kolorektálním karcinomem. Klin Onkol 2016;29(5):351-7.

13. Kondrup J, Rasmussen HH, Hamberg O, Stanga Z; Ad Hoc ESPEN Working Group. Nutritional risk screening (NRS 2002): a new method based on an analysis of controlled clinical trials. Clin Nutr 2003;22(3):321-36.

14. Dindo D, Demartines N, Clavien PA. Classification of surgical complications: a new proposal with evaluation in a cohort of 6336 patients and results of a survey. Ann Surg 2004;240(2):205-13.

15. MacFie J, Woodcock NP, Palmer MD, Walker A, Townsend S, Mitchell CJ. Oral dietary supplements in pre- and postoperative surgical patients: a prospective and randomized clinical trial. Nutrition 2000;16(9):723-8. 
16. Smedley F, Bowling T, James M, Stokes E, Goodger C, O'Connor O, Oldale $C$, Jones P, Silk D. Randomized clinical trial of the effects of preoperative and postoperative oral nutritional supplements on clinical course and cost of care. Br J Surg 2004;91(8):983-90.

17. Gillis C, Buhler K, Bresee L, Carli F, Gramlich L, Culos-Reed N, Sajob TT, Fenton TR. Effects of Nutritional Prehabilitation, With and Without Exercise, on Outcomes of Patients Who Undergo Colorecta Surgery: A Systematic Review and Meta-analysis. Gastroenterology 2018;155(2):391-410.e4.

18. Thoresen L, Frykholm G, Lydersen S, Ulveland H, Baracos V, Prado CM, Birdsell L, Falkmer U. Nutritional status, cachexia and survival in patients with advanced colorectal carcinoma. Different assessment criteria for nutritional status provide unequal results. Clin Nut 2013;32(1):65-72.

19. Poudineh $S$, Shayesteh F, Kermanchi J, Haghdoost AA, Torabi $P$ Pasdar Y, Azimi-Nezhad M, Safarian M, Hajifaraji M, Eslami-HasanAbadi S, Pournik O, Barkhidarian B, Norouzy A. A multi-centre survey on hospital malnutrition: result of PNSI study. Nutr J 2021;20(1):87.
20. Lopes JP, de Castro Cardoso Pereira PM, dos Reis Baltazar Vicente AF, Bernardo A, de Mesquita MF. Nutritional status assessment in colorectal cancer patients. Nutr Hosp 2013;28(2):412-8.

21. Buzby GP, Mullen JL, Matthews DC, Hobbs CL, Rosato EF. Prognostic nutritional index in gastrointestinal surgery. Am J Surg 1980;139(1):160-7.

22. Detsky AS, Baker JP, O'Rourke K, Johnston N, Whitwell J, Mendelson RA, Jeejeebhoy KN. Predicting nutrition-associated complications for patients undergoing gastrointestinal surgery. JPEN J Parenter Enteral Nutr 1987;11(5):440-6.

23. Dempsey DT, Mullen JL, Buzby GP. The link between nutritional status and clinical outcome: can nutritional intervention modify it? Am J Clin Nutr 1988;47(2 Suppl):352-6.

24. Klidjian AM, Foster KJ, Kammerling RM, Cooper A, Karran SJ. Relation of anthropometric and dynamometric variables to serious postoperative complications. Br Med J 1980;281(6245):899-901. 